\title{
Cervical Intraepithelial Neoplasia
}

National Cancer Institute

\section{Source}

National Cancer Institute. Cervical Intraepithelial Neoplasia. NCI Thesaurus. Code C3782.

Squamous or glandular intraepithelial neoplasia that affects the cervical mucosal epithelium. There is no evidence of stromal invasion. According to the degree of cellular atypia and the associated architectural changes, it is classified as low or high grade. 